\title{
Consequentialism, Indirect Effects and Fair Trade
}

\author{
ANDREW WALTON \\ University of St Gallen
}

\begin{abstract}
In this article I consider two consequentialist positions on whether individuals in affluent countries ought to purchase Fair Trade goods. One is a narrow argument, which asserts that individuals should purchase Fair Trade goods because this will have positive direct effects on poverty reduction, by, for example, channelling money into development. I argue that this justification is insufficient to show that individuals should purchase Fair Trade goods because individuals could achieve similar results by donating money to charity and, therefore, without purchasing Fair Trade goods. The second position has a wider focus. It notes both the direct effects of purchasing Fair Trade goods and possible indirect effects, such as the impact this might have on other individuals. I argue that certain actions, of which Fair Trade is one example, will be more likely to encourage individuals who would not otherwise contribute to poverty reduction to contribute and that this may produce additional positive value. Although space prohibits specific conclusions about Fair Trade, I note that considerations of this kind could give us reason to purchase such goods beyond those that issue from the direct effects of doing so and that, as such, they are crucial for determining whether individuals should purchase Fair Trade goods.
\end{abstract}

\section{INTRODUCTION}

Should individuals in affluent countries purchase Fair Trade goods? What is the connection between individual morality and Fair Trade? These are amongst the most obvious and pertinent questions one could ask about Fair Trade given that such goods are typically aimed at individual consumers and that their central selling point is their ethical appeal. They are also topical questions which are, unsurprisingly, attracting increasing attention in literature.

In this article I hope to make some contribution to developing debate in this area by considering a particular defence of Fair Trade. The viewpoint I wish to consider is broadly consequentialist. That is, it defends Fair Trade with reference to good outcomes. ${ }^{1}$ It is the argument, often found in public discourse and rhetoric on Fair Trade, that 'Fair Trade [sic] offers consumers a powerful way to reduce poverty'.

This line of argument could be mobilized in support of Fair Trade in one of two ways. First, it could appeal solely to the direct effects

1 This is not to say that views other than consequentialism do not value good outcomes; only that this focus is most typically associated with consequentialism.

2 FLO, 'What is Fairtrade?', <http://www.fairtrade.net/what_is_fairtrade.html> (2010). 
of purchasing Fair Trade goods. For example, it might be argued that purchasing Fair Trade goods is valuable because doing this transfers wealth to individuals who live in poverty, wealth which will alleviate their plight somewhat. Let us call this the narrow consequentialist justification (NCJ). Alternatively, the argument could be given a wider focus. It might be thought, for example, that purchasing Fair Trade goods helps transfer wealth to those in poverty and that it has some indirect effect, such as prompting others to contribute to poverty relief, which is also of positive value. The argument, then, would be that purchasing Fair Trade goods is valuable given this tout court contribution to poverty relief. Let us call this the wide consequentialist justification (WCJ).

Working from within a consequentialist perspective I make two sets of arguments about these justifications for Fair Trade.

First, I focus on the $N C J$, entering an existing debate which pits Hassoun and Philips in defence against Kurjanska and Risse in critique. Although I challenge certain specifics of their argument, I argue that Kurjanska and Risse's position seems the more plausible.

Second, however, I argue that the focus of Hassoun, Philips, and Kurjanska and Risse on the NCJ is something of a mistake and that, as such, although Kurjanska and Risse's position on it seems more tenable, this represents a rather hollow victory. I argue, rather, that the question of whether an individual should purchase Fair Trade goods cannot be answered without considering the WCJ. I show this with an example, demonstrating that actions which exhibit certain properties to wit, those which are suitably public and which garner wide support from a population - will be more conducive to prompting others to act in desirable ways and that this indirect effect can be of great significance in determining the overall impact of our actions. I then argue that since Fair Trade goods exhibit these properties, the purchase of such goods might be one case where this point has application. My conclusions are somewhat qualified since Fair Trade is not unique in exhibiting these properties, but my arguments should show there can be reasons to purchase Fair Trade goods beyond the direct effects of doing so and that further discussion of this subject should focus on the WCJ.

\section{THE NARROW CONSEQUENTIALIST JUSTIFICATION}

In the introduction to this article I noted a common way to argue for Fair Trade. This is the thought that individuals should purchase Fair Trade goods because doing so helps poverty relief. When advocates deploy this argument they usually appeal to only the direct effects of purchasing such goods. Public discourse emphasizes points such as providing producers with income sufficient to cover the costs of 
sustainable production or the channelling of funds into community development projects, such as education and health care. ${ }^{3}$ Similarly, in both Hassoun's and Philips's recent defences of Fair Trade, the emphasis is on how it increases the wages of producers, reduces their economic vulnerability, helps them to meet their basic needs, and allows them to educate their children better. ${ }^{4}$ In using this basis to argue that 'there is a strong case for a moral duty to buy Fair Trade products', these arguments appeal to the NCJ. ${ }^{5}$ The idea, in essence, is that individuals should act so as to reduce poverty and that since purchasing Fair Trade goods reduces poverty directly by, say, channelling money into development, individuals should purchase Fair Trade goods.

There are three ways in which this argument could be challenged. One would be to deny that individuals should act so as to reduce poverty. This is not an indisputable claim, but it is fairly uncontroversial, so I will bypass it here.

Second, the empirical premise of the argument - the claim that individuals can reduce poverty by purchasing Fair Trade goods - could be challenged. It can be challenged in one of two ways. First, it could be argued that Fair Trade has a directly negative effect, perhaps for those involved in Fair Trade networks or those excluded from them. Second, it could be argued that Fair Trade's long-term impact will be negative. Some have argued, for instance, that Fair Trade creates artificial markets by offering incentives to produce, say, coffee even though market prices show that it is already over-supplied. ${ }^{6}$ Others have argued that Fair Trade ties producers to unstable markets, such as primary goods production. ${ }^{7}$

There is not space here to conduct a comprehensive analysis of the impact of Fair Trade, but my sense is that Fair Trade has answered its critics on these matters. There is now a sizeable literature on the beneficial contribution Fair Trade has made to poverty reduction for

${ }^{3}$ See, for example, FLO, 'What is Fairtrade?'.

${ }^{4}$ N. Hassoun, 'Making Free Trade Fair', Carnegie Mellon Department of Philosophy Working Paper Series, Paper 356, <http://repository.cmu.edu/cgi/viewcontent.cgi?article $=1357 \&$ context $=$ philosophy $>$ (2011), pp. 15-19; J. Philips, 'Is There a Moral Case for Fair Trade Products? On the Moral Duty for Consumers to buy and for Governments to Support Fair Trade Products', The Impact of Fair Trade, ed. R. Ruben (Wageningen, 2008), pp. 240-3.

${ }_{5}^{5}$ Philips, 'Is There a Moral Case for Fair Trade Products?', p. 249.

${ }^{6}$ See, for example, B. Lindsay, 'Grounds for Complaint? Understanding the Coffee Crisis', Paper for the Centre for Trade Policy Studies, $16<\mathrm{http} / / / \mathrm{www}$. freetrade.org/ pubs/briefs/tbp-016.pdf > (2003).

7 See, for example, M. S. LeClair, 'Fighting the Tide: Alternative Trade Organisations in the Era of Global Free Trade', World Development 30.6 (2002), pp. 949-58; M. Kurjanska and M. Risse, 'Fairness in Trade II: Export Subsidies and the Fair Trade Movement', PPE 7.1 (2008), pp. 45-6. 
both Fair Trade workers and many beyond these networks. ${ }^{8}$ Responses have also been given to worries over Fair Trade's long-term impact. ${ }^{9}$ The artificial markets challenge is faulty because it neglects to note that Fair Trade is a brand and is, therefore, separated from the wider coffee market. Ultimately, Fair Trade caters to a niche market and is sustainable so long as demand meets supply within that market. It cannot create artificial markets for coffee in general any more than Rolex watches create artificial markets for watches in general. The argument that Fair Trade ties producers to unstable primary goods production is faulty, because it ignores strategies employed by Fair Trade to avoid this problem, notably the assistance offered to enable business diversification both horizontally - to production of other goods - and vertically - to the manufacturing stages of production (such as the roasting of coffee beans), which capture higher returns and suffer less from market fluctuations. Of course, all this research could be questioned, but given the available evidence, it seems safe to assume that purchasing Fair Trade goods does contribute positively to poverty reduction.

The third option for challenging the NCJ is what we might call 'the comparative challenge'. ${ }^{10}$ The comparative challenge accepts that purchasing Fair Trade goods will reduce poverty. However, it highlights that purchasing Fair Trade goods is not the only way, nor necessarily the best way, one could achieve this goal. For example, one can also reduce poverty by donating money to Oxfam or UNICEF. So, we 'must think of Fair Trade', as Kurjanska and Risse put it, as only 'one possible development strategy'. ${ }^{11}$ The problem this creates for the NCJ is simple. If similar outcomes could be achieved by other means, consequentialists do not have much reason to value the purchase of Fair Trade goods in particular. They may still think that the purchase of Fair Trade goods is a worthy action. But since their main interest, at least on the terms of the $N C J$, is what individuals directly contribute to poverty relief, they are likely to feel largely indifferent towards individuals

8 This research is nicely summarized in Hassoun, 'Making Free Trade Fair', pp. 15-19. See also the collection of articles in The Impact of Fair Trade, ed. R. Ruben (Wageningen, 2008).

9 See M. A. Littrell and M. A. Dickson, Social Responsibility in the Global Market: Fair Trade of Cultural Products (London, 1999), pp. 61-112; S. Mohan, Fair Trade without the Froth: A Dispassionate Economic Analysis of 'Fair Trade' (London, 2010), pp. 34-46.

${ }_{10}$ I should note that I have explored the comparative challenge in detail elsewhere (A. Walton, 'The Common Arguments for Fair Trade', Political Studies, forthcoming). An argument with a similar thrust can also be found in Kurjanska and Risse, 'Fairness in Trade II', pp. 43-9. As such, what follows is a stylized version of the argument, shortened to allow space for the other arguments of this article. I refer readers who desire more detail to the above texts.

11 Kurjanska and Risse, 'Fairness in Trade II', pp. 46-7. 
who do not purchase Fair Trade goods provided that these individuals undertake other actions that will have a similar effect. They certainly would be unlikely to conclude that individuals ought to purchase Fair Trade goods, at least in the strong sense of the word 'ought'.

Hassoun has responded to Kurjanska and Risse's statement of this challenge by arguing that empirical evidence is needed to determine whether the objection succeeds. ${ }^{12}$ As the argument relies on the factual claim that other actions would have similar effects, this is true. However, Hassoun rather underestimates the challenge. Her approach of demonstrating Fair Trade's record in poverty relief is not sufficient to refute it. Nor is it enough to show that Fair Trade has a generally better record than aid or than certain charities. In all of these cases the comparative challenge can be restated with reference to specific charities - to wit, those with better records. Rather, in order to refute the challenge whilst retaining the focus of the NCJ, it must be shown that, in terms of directly reducing poverty, purchasing Fair Trade goods is an irreplaceable action. It remains an empirical question whether or not this is the case. However, the sheer magnitude of what would be required to rebut the comparative challenge surely suggests it should be deemed prima facie to refute the NCJ.

Now, it is important to clarify what this shows. It does not give us reason to condemn Fair Trade. In some instances Fair Trade may be an optimal poverty reduction strategy and in most cases purchasing Fair Trade goods and donating to charity will probably have similar direct effects. As such, even in light of the comparative challenge, a consequentialist should view Fair Trade as, at least, one acceptable way to contribute directly to reducing poverty.

Kurjanska and Risse conclude that since the best strategy for poverty relief depends on context, 'while sometimes there is a rightful claim on consumers to buy Fair Trade products, other times there is not'. ${ }^{13}$ This, I think, is not quite right. Few consequentialists think that assessing every action on its individual merits is what consequentialism requires. Imperfect information and time-constraints are just two reasons why this is not optimal from a consequentialist perspective. Given these limitations, often the best policy is to adopt a general practice that, on average, will be conducive to promoting the good. This is often how consequentialists defend the idea of rights. With similar reasoning, it might be argued that since Fair Trade can be deemed a generally profitable poverty reduction strategy, undertaking a general practice of purchasing Fair Trade goods would be reasonable.

12 Hassoun, 'Making Free Trade Fair', p. 6.

13 Kurjanska and Risse, 'Fairness in Trade II', p. 48. 
Nevertheless, what I think the comparative challenge does show is that if we consider only the direct effects, there is no reason to adopt a general practice of purchasing Fair Trade goods as opposed to, say, a general practice of donating money to charity. Since both are likely to produce positive direct results, both are acceptable general practices, but since they are likely to produce similar results, this perspective gives no obvious reason to favour one over the other. With respect to the choice between these options, Kurjanska and Risse are right in saying that to argue that individuals ought to purchase Fair Trade, it is not enough to note that doing so directly reduces poverty; one must also show it passes 'the test of being a development strategy superior to . . available alternatives'. ${ }^{14}$ Since it seems unlikely that this will be the case in all, or even many, scenarios, they are also right to conclude that emphasis on how one can directly reduce poverty - that is, the approach of the NCJ - is insufficient to show that individuals ought to purchase Fair Trade goods, at least in a strong sense.

\section{THE WIDE CONSEQUENTIALIST JUSTIFICATION}

In closing their article, Kurjanska and Risse write that, beyond the question of direct contribution to development, 'it is hard to see how to make [Fair Trade's] case stronger'. ${ }^{15}$ If this were true, discussion of Fair Trade could end with the conclusion noted above: that Fair Trade is, at best, one way to meet an imperfect duty to relieve poverty. However, Kurjanska and Risse's statement seems false to me. Indeed, my sense is that not only are the issues raised by the $N C J$ not all we can say about Fair Trade, but that focus only on the $N C J$ is not even able to answer the question of whether individuals should purchase Fair Trade goods.

In this section I aim to show this by highlighting that there are many matters of interest to a consequentialist beyond the direct effects of our actions and that these matters are of clear relevance to the question of Fair Trade. I will not attempt to develop an argument for the precise conclusion that individuals should purchase Fair Trade goods because my arguments on the importance of the indirect effects of our actions require the majority of the space available. So, I will limit myself to demonstrating this point, highlighting its relevance to Fair Trade, and concluding that the question of whether individuals should purchase Fair Trade goods can be answered only with reference to the WCJ.

${ }^{14}$ Kurjanska and Risse, 'Fairness in Trade II', p. 45.

15 Kurjanska and Risse, 'Fairness in Trade II', p. 49. 
The argument I will offer has three premises:

1. Some actions will be more likely than others to prompt contributions to poverty relief from individuals who would not otherwise contribute.

2. Undertaking these actions is more likely to result in a higher contribution to poverty relief and, therefore, should be deemed preferable from a consequentialist perspective.

3. Purchasing Fair Trade goods might be considered one such action.

These three premises will occupy me over the next three subsections respectively. I will then respond to some objections before concluding.

\section{Encouraging contributions}

The starting point for my argument is to highlight an issue that presumably is widely known: that there are some individuals around us who do not contribute to poverty relief. That such individuals exist in all affluent countries is something that requires little evidence.

In addition, note that, for each non-contributor, there is a psychological aspect to his or her behaviour. For example, research shows that many do not contribute because they require some assurance that others are doing likewise and they do not feel that they have this assurance. ${ }^{16}$ It is also undoubtedly the case that some do not contribute for self-interested reasons. There are presumably other reasons as well.

These factors are important because they highlight an opportunity for encouraging non-contributors to contribute. If conditional contributors can be assured that others are making a contribution, they will be encouraged to contribute. ${ }^{17}$ Similarly, if we can structure the circumstances of a self-interested person such that making a contribution becomes worthwhile for selfish reasons, she may be encouraged to contribute.

How might we take advantage of this opportunity? Of course, numerous things might encourage contributions. Here, I will concentrate on one: the way in which our actions can encourage others to contribute. It is evidently the case that our behaviour can prompt actions from others. This is shown from large-scale scenarios, where social etiquette can structure how individuals act, to small-scale scenarios, such as the way in which people often mirror each other's body language.

Further, it is undoubtedly the case that an action with certain features will be more likely to affect others. Two such conditions are

\footnotetext{
16 This research is summarized in P. Singer, The Life You Can Save: How to Do Your Part to End World Poverty (New York, 2010), pp. 64-5.

17 See Singer, The Life You Can Save, pp. 64-5.
} 
as follows. First, it must be an action that non-contributors believe contributes to a goal. Call this the subjectivity condition. Second, it must be an action that attracts appropriate attention. Call this the publicity condition.

To demonstrate the importance of these conditions, consider an example. Imagine that there is a local play-area for families and that it requires the contributions of a number of individuals to keep it in good condition. There are two individuals, Clive and Deborah. Both are willing to contribute. However, Deborah is a conditional contributor. She feels that it would be unfair for her to contribute if others do not. As such, she will contribute only if she is assured that others are contributing.

Now consider Clive's options. Imagine that Clive can undertake one of two actions: 'mending broken playground rides' or 'making a financial donation'. One issue Clive must consider is whether these actions do make a genuine contribution to maintaining the play-area. If an action does not meet this condition, undertaking the action will be of little use. But let us imagine that both actions do meet this condition. Once this is established, it is also worth considering the subjectivity and publicity conditions.

Suppose, for example, that Deborah believes making a financial contribution does not constitute a genuine contribution, perhaps because she feels that it is not in keeping with the spirit of the project. In this instance, if Clive acts by making a financial contribution, he will not have much chance of prompting Deborah's contribution. Since she does not believe that this constitutes a contribution, she will perceive his action as inaction. She will not be assured that others are contributing and she will not contribute. Similarly, imagine that one's only means of making a financial contribution is very secretive. In this instance, again, Clive can have little effect on Deborah by making a financial contribution. Without evidence of Clive's contribution, Deborah is unlikely to have the assurance she desires and she will not contribute. In both instances, Clive can hope to have an influence on Deborah only if he mends broken rides.

The same seems true for scenarios involving non-contributors with other motivations. Just as in the case of conditional contributors, it is difficult to see how any individual would be encouraged to contribute by others taking actions which she does not believe constitute contributions or of which she does not have knowledge. Inversely, if any action is to encourage her to contribute, it must have these features.

Note also that an action meeting the publicity condition could have an impact in terms of altering the social atmosphere. For example, if Clive mends broken rides within the view of Deborah and an audience of others, it might create some social pressure on Deborah to do the 
same. Many social conventions work in this way. Group tipping in restaurants is a good example. Similarly, Deborah might feel more inclined to contribute because she observes the gratitude shown to Clive by others and she perceives an opportunity to curry favour with them. Contributing in private, on the other hand, can have none of these effects.

It must be admitted that there is no certainty that actions which meet the subjectivity and publicity conditions will prompt contributions from non-contributors. In addition, it should be acknowledged that the extent to which actions meet these conditions might be a matter of degree. A lot may depend on context. I will return to these matters below.

For the moment, though, I hope I have shown that, at least ceteris paribus, actions which have these features will stand a higher chance of prompting contributions from non-contributors than actions which do not have these features.

\section{Consequentialism and indirect effects}

The second point I wish to make in this section is that in scenarios, such as our own, where there is a group of non-contributors, the impact of one's actions on advancing goals such as poverty reduction can vary considerably to the extent that these actions meet the subjectivity and publicity conditions. In particular, if some actions meet these conditions to a greater extent than other actions, the former have a higher chance of bringing about a greater overall contribution to poverty reduction.

To demonstrate this, imagine two people: Alan and Betty. Alan is considering how to reduce poverty. Betty is a non-contributor. Alan has two actions available to him: X and Y. Let us assume that actions $\mathrm{X}$ and $\mathrm{Y}$ both have a similar direct impact (of value $\mathrm{N}$ ) on advancing poverty reduction, but that action $\mathrm{X}$ meets the subjectivity and publicity conditions to a greater extent than Y. Now, as noted above, it is not the case that actions meeting the subjectivity and publicity conditions will necessarily prompt the contributions of others. It must also be noted that the actions will meet the conditions by matters of degree and so both will have some probability of prompting a contribution. However, what was argued above is that actions meeting the subjectivity and publicity conditions to a greater extent will have a higher probability of prompting a contribution. We acknowledge this by assigning a probability to the likelihood of action X prompting Betty's contribution $(\mathrm{P})$ and assigning a probability to the likelihood of action $\mathrm{Y}$ prompting her contribution ( $\mathrm{Q}$ ) and by assuming that the probability assigned to $\mathrm{X}$, which meets the subjectivity and publicity conditions to a greater extent, is higher than that assigned to $\mathrm{Y}$ (that is, that $\mathrm{P}>\mathrm{Q}$ ). In this scenario, the overall expected utility of Alan's action is as follows: 
Table 1. The effect of indirect effects

\begin{tabular}{lllll}
\hline A's action & $\begin{array}{l}\text { A's direct } \\
\text { impact }\end{array}$ & B's action & $\begin{array}{l}\text { B's direct } \\
\text { impact }\end{array}$ & $\begin{array}{l}\text { Total } \\
\text { contribution }\end{array}$ \\
\hline $\mathrm{X}$ & $\mathrm{N}$ & $\mathrm{PX}$ & $\mathrm{PN}$ & $\mathrm{N}(1+\mathrm{P})$ \\
$\mathrm{Y}$ & $\mathrm{N}$ & $\mathrm{QY}$ & $\mathrm{QN}$ & $\mathrm{N}(1+\mathrm{Q})$ \\
\hline
\end{tabular}

What this table shows is the following. In a world, such as our own, where a number of non-contributors exist, some actions can be expected to produce utilities beyond their direct effects. In particular, some actions, such as actions which meet the subjectivity and publicity conditions to a greater extent, have a higher probability of also prompting non-contributors to contribute to poverty relief than other actions. Consequently, undertaking these actions can be expected to bring about a higher overall contribution to poverty relief than actions with lower chances of having these effects.

The implications of this point for a consequentialist perspective are irresistible. If two actions have similar direct effects, but one has a higher chance of bringing about valuable indirect effects and, therefore, can be deemed to have a higher expected utility, a consequentialist should opt for this action.

With this point in mind, let us return to the question of Fair Trade.

\section{Agreement, publicity, and Fair Trade}

The final stage of my argument involves highlighting that Fair Trade meets the subjectivity and publicity conditions fairly well.

It meets the publicity condition in a fairly obvious sense. The typical sites of Fair Trade consumption are public forums, such as the supermarket or coffee shops. In addition, Fair Trade has particular ways of attracting attention. By placing the Fair Trade label on certain goods, Fair Trade attempts to portray the image that one chooses either the fair option or the unfair option. The juxtaposition this creates gives a certain salience to Fair Trade goods. This is undoubtedly beneficial in terms of catching the attention of others.

There is also evidence to suggest that Fair Trade meets the subjectivity condition. For example, it is of note that both the recognition of the Fair Trade label and the popularity of Fair Trade have risen steadily over the last twenty years, including continuing to rise even during recession. ${ }^{18}$ It is also of note that opinion polls

\footnotetext{
18 See Fairtrade Foundation, 'Global Fairtrade sales increase by $22 \%$ ', <http://www. fairtrade.org.uk/press_office/press_releases_and_statements/jun_2009/global_fairtrade_ sales_increase_by_22.aspx $>(2009)$ and D. Milmo, 'Fairtrade's Annual Sales Defy
} 
confirm that Fair Trade is popular amongst consumers. ${ }^{19}$ None of this specifically shows that purchasing Fair Trade goods is the subject of an all-encompassing consensus, but it does suggest that Fair Trade meets the subjectivity condition reasonably well.

It is important to note that Fair Trade is not unique in meetings these conditions. For example, there are various ways of donating money to charity that are fairly public, such as dropping money into charity boxes on the street or in the supermarket.

However, it is also important to note that there are forms of charitable giving that clearly do not satisfy the subjectivity and publicity conditions. For example, online donations and direct debit payments will not meet the publicity condition to any great extent. There is also evidence that a notable percentage of people object to the high administrative costs of aid. ${ }^{20}$ This might suggest that donations to large, bureaucratic charities will not meet the subjectivity condition very well. ${ }^{21}$

There is also evidence that a higher proportion of the UK population deem fairer trading an appropriate response to poverty than think this about donating to charity. ${ }^{22}$ This might even suggest that purchasing Fair Trade goods meets the subjectivity condition to a greater extent than donating to charity quite generally.

At any rate, what we can certainly deduce is that the purchase of Fair Trade goods is amongst a set of actions that will be clearly superior to at least some other forms of contributing to poverty relief in terms of meeting the subjectivity and publicity conditions. What follows from this is that there is a set of actions, of which purchasing Fair Trade goods is one example, that can be more readily expected to generate

Recession to Pass £1bn', The Guardian, <http://www.guardian.co.uk/business/2011/ feb/28/fairtrade-sales-rise-despite-recession $>$ (2011).

19 See, for example, IGD, 'Interest in Fair Trade Doubles', <http://www.igd.com/ index.asp?id $=1 \&$ fid $=6 \&$ sid $=25 \& \operatorname{cid}=200>(2008)$.

${ }^{20}$ Ipsos MORI, 'A Survey of Public Attitudes to the Charity Commission', <http://www.ipsos-mori.com/researchpublications/researcharchive/1767/A-Surveyof-Public-Attitudes-to-the-Charity-Commission.aspx $>$ (1999).

${ }^{21}$ One objection that might be raised here is that larger, more bureaucratic charities can be more cost-effective owing to economies of scale, thus offsetting the disvalue of not garnering widespread popularity. For what it is worth, my understanding is that in practice these charities are not usually more efficient. On this see Giving What We Can, 'Recommended Charities', <http://www. givingwhatwecan.org/resources/recommended-charities.php> (2011) and Giving What We Can, 'Charity Comparisons', <http://www.givingwhatwecan.org/resources/charitycomparisons.php $>$ (2011). However, as I will highlight in the next section, even if this objection is accurate, it does not undermine my broader arguments.

${ }_{22}$ M. B. Brown, Fair Trade: Reform and Realities in the International Trading System (London, 1993), p. 180; K. Bird and D. Hughes, 'Ethical Consumerism: The Case of "Fairly-Traded" Coffee', Business Ethics: A European Review 6.3 (1997), pp. 159-67, at 161. 
indirect contributions to poverty relief than another set of actions. Moreover, if the arguments of the first section of this article - that in most instances, donations to charity and purchases of Fair Trade goods will have similar direct effects - are correct, these indirect effects would mean that these actions could be expected to generate higher overall utility. This would be sufficient to show that a consequentialist should say that individuals ought to opt for them in the strong sense of the word 'ought'.

\section{Response to objections}

I do not have space to consider all of the objections that could be levelled against my arguments here. Instead I will consider three that have been raised regularly.

The first is the question of whether any individual actions really could prompt others into action. One reason why they might not is that observation of individual actions might not be sufficient to provide, say, individuals seeking assurance with stable knowledge that 'others' are contributing, as opposed to simply one or two other individuals.

My response to this is to deny that these two issues can be distinguished in this fashion, at least in terms of the usual inferences we make about behaviour patterns. Most belief about behaviour patterns is based on observing a number of individuals undertaking an action and drawing inferences. For example, my belief that Coca-Cola is widely purchased is based primarily on hearing a number of others ordering it. Similarly, if people overhear a number of others ordering Fair Trade coffee on a regular basis, it is likely that they will infer from this that these are regular Fair Trade consumers and, if the Coca-Cola example holds, the belief that Fair Trade is widely purchased.

Here a second objection may be raised. One problem with inferring conformity with a practice from what happens in one's local coffee shop, it might be thought, is that here, and more generally, I move within a specific population demographic. The main worry that this might be thought to raise for my view is that since people move in different demographic contexts and will witness and be influenced mainly by peer groups, purchasing Fair Trade goods, for instance, will not have an impact across demographic boundaries.

I should say that I doubt demographic separation is this strict in most affluent countries. There is certainly no problem establishing many other behaviour patterns across these demographics. ${ }^{23}$ Even if demographic separation is this strict, though, it does not affect my argument since the case in favour of public donations to charity and

${ }^{23}$ On this see J. Elster, The Cement of Society: A Study of Social Order (Cambridge, 1989). 
Fair Trade would still hold within demographic groups. Moreover, it will remain the case that, if any actions are likely to influence others outside one's peer group, it is likely to be actions that meet the subjectivity and publicity conditions to a higher extent. As such, the central thrust of my argument appears to have application even in this scenario.

The final objection that must be noted here is the claim that my arguments are too theoretical. Of course, ultimately, whether the above considerations on indirect effects demonstrate that purchasing Fair Trade goods (or undertaking another of the actions within its set) is the best way to reduce poverty tout court requires numerous empirical calculations that have been omitted here. It might still be possible that donations to certain charities will be so directly effective that this outweighs the indirect benefits of contributing to poverty relief publically or that informing others that one donates to charity privately would be sufficient to provide assurance to conditional contributors.

For what it is worth, I do not think that these objections succeed. For the reasons I noted above, my sense is that the direct effects of purchasing Fair Trade goods and donating to various charities will often be similar, at least over time. Similarly, I doubt that those seeking assurance of the contribution of others will find discussion of contributions as assuring as observation of them. This would suggest that public actions are still more likely to prompt the contribution of others.

Nevertheless, I will leave these objections unanswered in the strict sense because even if they are accurate, my arguments still show that one cannot determine how one should act from a consequentialist perspective without at least considering the indirect effects of our actions. For example, it would be impossible to know whether donating to charity is so directly effective that it outweighs the benefits of purchasing Fair Trade goods without calculating the direct and indirect benefits of both. What follows from this is that work focused only on the NCJ is simply unable to address the question of whether individuals should purchase Fair Trade goods from a consequentialist perspective adequately. As such, in conclusion, I submit that future work must consider the question from the perspective of the wide consequentialist justification. ${ }^{24}$

andrew.walton@unisg.ch

${ }^{24}$ I owe thanks to an audience at the University of Warwick's Centre for Ethics, Law, and Public Affairs for comments on an earlier draft of this article and special thanks to Matthew Clayton, Chloé Lewis and Dorothea Baur for extensive discussion of it. 